\title{
AS METAS EDUCACIONAIS COMO EIXOS ARTICULADORES DOS RELATÓRIOS DO DESENVOLVIMENTO HUMANO DA ONU
}

Maria José de Rezende*

RESUMO: Através de uma pesquisa documental, esta análise detectou que as propostas, feitas aos Estados nacionais no campo educacional, dão o norte das ações sugeridas tanto antes como depois da Declaração do Milênio subscrita por 191 países em setembro de 2000. Verifica-se que os três pilares (renda, longevidade e educação) do Índice do Desenvolvimento Humano aparecem interligados no interior dos RDHs. Todavia, fica demonstrado que os déficits educacionais, o não acesso aos bancos escolares, as taxas de analfabetismos, a não universalização da educação para homens e mulheres acabam por destruir qualquer possibilidade de melhoria da renda e da longevidade. Por isso, o desenvolvimento humano é mostrado como inteiramente dependente dos avanços educacionais. Sem eles não há avanços em quaisquer outras áreas.

Palavras-chave: Educação; Desenvolvimento Humano; Desigualdades; Pobreza.

\section{EDUCATIONAL GOALS AS ARTICULATING AXES OF THE HUMAN DEVELOPMENT REPORTS OF THE UNITED NATIONS - UN}

ABSTRACT: Through documentary research, this analysis found that the proposals made to the national States in the area of education guide the actions suggested before and after the 'Millennium Declaration', signed by 191 countries in September 2000. It seems that the three pillars (income, longevity and education) of the Human Development Index (HDI) appear intertwined within the Human Development Reports. However, it is demonstrated that the educational deficits, no access to school, illiteracy rates, and non-universal education for men and women undermine any possibility of improving income and longevity. Therefore, human development is shown as entirely dependent on education. There is no progress in other areas without improvement in education.

Keywords: Education; Human Development; Inequalities; Poverty.

\footnotetext{
*Doutora em Sociologia pela Universidade de São Paulo (USP) e Professora Associada da Universidade Estadual de Londrina (UEL). E-mail mjderezende@gmail.com
} 


\section{INTRODUC̣ÃO}

Desde a primeira edição dos Relatórios do Desenvolvimento Humano (RDHs), publicados a partir de 1990 pelo Programa das Nações Unidas para o Desenvolvimento (PNUD), verifica-se que os desafios (os quais dizem respeito ao ensino, ao aprendizado, aos investimentos destinados a desenvolver capacidades e habilidades que levem pessoas, seja individualmente seja em grupos, a um crescente envolvimento tanto na melhoria da educação básica quanto na expansão das oportunidades sociais e políticas) no campo educacional têm sido a coluna central no processo de combate à pobreza, às exclusões, às privações e às desigualdades de chances (de renda, de trabalho, de instrução) que atingem $1 / 3$ da população mundial.

A discussão empreendida pelos RDHs sobre o papel primordial da educação no processo de desenvolvimento humano diz respeito ao fato de que este tem como padrão de medida o Índice de Desenvolvimento Humano (IDH) que se baseia, primordialmente, em três componentes básicos: renda, longevidade e educação.

\footnotetext{
Para aferir a longevidade, o indicador utiliza números de expectativa de vida ao nascer. O item educação é avaliado pelo índice de analfabetismo e pela taxa de matrícula em todos os níveis de ensino. A renda é mensurada pelo PIB per capita, em dólar PPC (paridade do poder de compra, que elimina as diferenças de custo de vida entre os países). Essas três dimensões têm a mesma importância no índice, que varia de zero a um [...] (PROGRAMA DAS NAÇÕES UNIDAS PARA O DESENVOLVIMENTO, 2001, p. 1).
}

Em tais condições, todos os relatórios da década de 2000 vão ter como objetivo medir até que ponto está, ou não, havendo, nos diversos países ao redor do mundo, avanços e/ou recuos nas metas educacionais estabelecidas com base tanto num parâmetro de desenvolvimento humano que procura avançar para além "[...] da acumulação de riqueza e do crescimento do Produto Interno Bruto (PIB) e de outras variáveis relacionadas à renda [...]” (SEN, 2005, p. 29), quanto nas metas estabelecidas na Declaração do Milênio $^{1}$ (NAÇÕES UNIDAS, 2000), aprovadas em setembro de 2000 na Conferência Geral das Nações Unidas.

Os RDHs da década de 1990, antes de estarem em vigor os ODMs (Objetivos do Desenvolvimento do Milênio), já envidavam grandes esforços em demonstrar que as estratégias de desenvolvimento humano 
estavam fundadas na ampliação das oportunidades educacionais para todos. Inspirados na idealização de um tipo de desenvolvimento que leva em conta, além da renda, o acesso a uma melhor nutrição, ao saneamento básico, ao atendimento médico e à escolarização universal de meninos e meninas $^{2}$, os relatórios produzidos pelo PNUD, a partir de 2001, estarão voltados para a exposição das (im)possibilidades que muitos países vêm encontrando para viabilizar o compromisso assumido por 191 países que assinaram a Declaração do Milênio.

No âmbito deste artigo, não será feita uma análise das diversas áreas (saúde, saneamento, direitos sociais, políticos, segurança, nutrição, participação política, democratização, igualdade de gênero, etc.) ${ }^{3}$ que compõem o desenvolvimento humano. Serão discutidas as propostas feitas por alguns RDHs da década de 1990 para superar os desafios que, no campo educacional, os países estão encontrando para caminhar rumo a um processo de geração das condições de combate à pobreza, à privação, às exclusões e às desigualdades de oportunidades que impedem melhorar os Índices de Desenvolvimento Humano (IDH).

Parte-se, então, do princípio de que as metas educacionais postas nos RDHs inspiram-se nas propostas de expansão das capacidades e das oportunidades feitas por Amartya Sen, que buscou, desde as últimas décadas do século XX, elaborar uma concepção de desenvolvimento que tivesse em seu centro o combate a todas as formas de privação humana. O economista indiano insiste que as políticas econômicas decididamente voltadas para melhorias sociais são aquelas que se propõem a aumentar a alfabetização, a escolarização e muitas outras oportunidades sociais e políticas (SEN, 2006).

Assim, os próprios relatórios enfatizam que suas propostas estão inspiradas no cientista anteriormente mencionado e também em outros, como o paquistanês Mahbub Ul Haq. Trata-se de adesão a uma inspiração e não de filiação, já que a própria natureza dos debates presentes nos documentos do PNUD é de caráter específico, pois estes estão muito mais preocupados em realizar uma abordagem propositiva do que em se embrenhar num debate teórico-conceitual sobre a teoria da escolha social que forneceu as bases para uma teoria econômica que, segundo Sen $(1988,2001)$, tornou possível a existência das proposições em torno do desenvolvimento humano.

O ensinamento de Amartya Sen - o qual considera que "[...] o desenvolvimento tem de estar relacionado, sobretudo, com a melhoria da vida 
que levamos e das liberdades que desfrutamos [...]" (SEN, 2005, p. 29) - está na base das afirmações dos RDHs, segundo as quais os avanços educacionais têm de estar no centro do combate às muitas formas de privações. Ensina o economista indiano:

Uma concepção adequada do desenvolvimento deve ir muito além da acumulação de riqueza e do crescimento do Produto Nacional Bruto e de outras variáveis relacionadas à renda. Sem desconsiderar a importância do crescimento econômico, precisamos enxergar muito além dele. [...] Expandir as liberdades que temos [...] não só torna nossa vida mais rica e mais desimpedida, mas também permite que sejamos seres sociais mais completos, pondo em prática nossas volições, interagindo com o mundo em que vivemos e influenciando esse mundo [...] (SEN, 2005, p. 29).

Em indicações dessa natureza, estão baseados os dizeres dos RDHs das décadas de 1990 e de 2000 que insistem em afirmar que os avanços na área da educação se refletem em todas as demais áreas. As melhorias sociais e políticas dependem, segundo os RDHs, da universalização do ensino básico. Melhores condições de renda, de trabalho, de participação política, de expansão da democracia, de equalização de gênero e de acesso à saúde dependem de avanços educacionais. Estes, por sua vez, dependem também da reversão paulatina da pobreza absoluta e da urbanização extremamente precária, que, pela ausência de serviços básicos como saneamento, água potável, moradia adequada, etc., põe enormes empecilhos para a universalização da educação básica.

Note-se que os RDHs, ao falarem da universalização do ensino, estão preocupados essencialmente com a educação básica. Isso, que já estava posto nos relatórios da década de 1990, passa a estar reafirmado na Declaração do Milênio que passou a orientar os relatórios da década de 2000. O objetivo número 2, dos ODMs, tem como meta garantir a conclusão do ensino fundamental para todos(as) meninos(as). Essa meta deve ter sua medição aferida com base em dois indicadores: taxa líquida de matrícula no ensino fundamental e número de jovens (de 15 a 19 anos) que finalizaram o ensino fundamental.

Observe-se que os RDHs, assim como os ODMs, estão, essencialmente, preocupados com a educação básica. Mesmo porque eles estão mais atentos às condições dos países extremamente pobres em que há, ainda, taxas altíssimas de analfabetismos e de inacessibilidade de homens e mulheres aos bancos escolares. Na América Latina, por exemplo, os 
organismos (Comissão Econômica para a América Latina - CEPAL, por exemplo) ligados às Nações Unidas sugerem que

[...] os países devem não só procurar a efetiva universalização do ensino fundamental, mas também ampliar a cobertura da educação pré-escolar e de nível médio, bem como melhorar a equidade e a qualidade de seus sistemas educacionais [...] (COMISSÃO ECONÔMICA PARA A AMÉRICA LATINA E O CARIBE, 2005, p. 3).

Há países na América Latina, tais como El Salvador, Guatemala, Honduras e Nicarágua, que terão, ainda em 2015, um índice altíssimo (de 18\% a 31\%) de jovens que não completarão o ciclo básico de ensino (COMISSÃO ECONÔMICA PARA A AMÉRICA LATINA E O CARIBE, 2005, p. 4). Todo debate posto pelos RDHs visa indicar caminhos possíveis para reverter essa estimativa. Todos os avanços, por menores que sejam, têm sido exaltados. Em 2005, uma reportagem do PNUD destacava que havia países na África (Zâmbia, por exemplo) que, mesmo em condições muito difíceis, estavam conseguindo melhorar tanto o investimento público na educação (o que passou de 5,3 para 7,6 milhões de dólares) quanto as taxas de matrículas entre os mais pobres e o acesso das meninas aos bancos escolares. O desafio era, no entanto, conter a evasão que punha em risco tais avanços (INFANTE, 2005, p. 1).

O problema central deste artigo é, então, verificar de que modo os RDHs, da década de 1990, estabelecem ligações entre investimento na educação e combate à pobreza absoluta e de que maneira a melhoria educacional leva os indivíduos a vencerem os obstáculos à empregabilidade, ao acesso a um rendimento mais adequado às necessidades básicas, ao acesso à saúde, à informação e à participação política. As análises das propostas, na área educacional, contidas nos RDHs da década de 2000 - que vão insistir na necessidade de cumprimento dos Objetivos do Milênio como forma de retirar as pessoas da condição de miserabilidade absoluta - serão feitas num outro artigo dada a extensão dos respectivos relatórios anuais editados pelo PNUD/ONU.

\section{OS RDHS E OS DEBATES SOBRE OS AVANÇOS EDUCACIONAIS COMO ANTÍDOTOS CONTRA A POBREZA ABSOLUTA E O DESEMPREGO NA DÉCADA DE 1990}

É evidente que os relatórios do Pnud estão inspirados nas discussões que vêm associando, ao longo do século XX, investimento na educação e 
combate à pobreza e às desigualdades. Foram muitos os debates sobre isso nas últimas décadas. Muitas reflexões sobre desenvolvimento social buscavam demonstrar que havia forte similaridade entre melhoria educacional e melhoria social (BOMFIM, 1993; AZEVEDO, 1958a, b; TEIXEIRA, 1987). Foi construída, durante anos, uma associação entre déficits educacionais e miserabilidade. Miguel B. Parada (2002), em Educação e pobreza: uma relação conflitiva, afirma que, quando se constrói essa ligação entre menor escolaridade e condição de pobreza, a educação tem sido tomada como sinônimo de escolarização. Enquanto alguns cientistas (WAISELFISZ, 1998; KLIKSBERG, 1997, 2002; BUARQUE, 1994) e técnicos constroem laços aproximando a ausência de escolarização e a persistente miserabilidade, o autor acima chama a atenção para a dificuldade de fazer uma correlação automática entre essas duas condições. Ele diz que a teoria do capital humano

[...] faz da igualdade de oportunidades o centro da política educativa para superar a pobreza, e curiosamente tem dificuldades de explicar o porquê da existência da desigualdade. Por que, se a política educativa trata de oferecer 'educação para todos', persiste a desigualdade de oportunidades? (PARADAS, 2002, p. 68).

$\mathrm{Na}$ América Latina quem melhor respondeu a essa questão posta por Paradas foi Celso Furtado (1999, 2002) ao enfatizar que é necessário, nos países pobres que acumulam desigualdades exorbitantes e atrasos no investimento do fator humano, combinar ações que revertam tanto a concentração patrimonial e da renda quanto a precariedade educacional. Ganha relevância, neste processo, um enfoque pautado no seguinte entendimento: "Para participar da distribuição da renda, a população necessita estar habilitada por títulos de propriedade ou pela inserção qualificada no sistema produtivo [...]" (FURTADO, 2002, p. 16). Por isso, para ele, a noção de "[...] desenvolvimento global [...] inclui mudanças ao nível das estruturas [...]” (FURTADO, 1977, p. 126).

O debate sobre a necessidade de investir no fator humano não pode ser reduzido, como faz, às vezes, Paradas, a uma preocupação somente dos liberais. Estes, certamente, convertem a teoria do capital humano em políticas compensatórias focalizadas nos grupos mais pobres como forma de habilitá-los a se virarem por conta própria e resolverem seus problemas através de melhor participação no mercado de trabalho. Mas não é esse o enfoque que se encontra em Amartya Sen e Celso Furtado, por exemplo. Mesmo havendo diferenças entre esses dois últimos, pode-se dizer que 
os dois estão de acordo em relação ao papel da educação no processo de alavancar o desenvolvimento social e humano. A educação, segundo eles, habilita os indivíduos a serem incluídos socialmente. Todavia, Furtado volta-se mais do que o primeiro para a necessidade de reversão dos bloqueios estruturais potencializadores das disparidades sociais. Isso porque, para o economista brasileiro, em sociedades extremamente desiguais, o enfoque habilitador ${ }^{4}$ pode não surtir o efeito inclusivo ${ }^{5}$ que se imagina ${ }^{6}$. Enfim, para Celso Furtado é preciso que haja simultaneamente distribuição da renda, desconcentração patrimonial e habilitação.

Um amplo programa social deve dar prioridade à habitação e à educação, antes do investimento produtivo. A educação interfere no tempo, e, melhorando-se a qualidade do fator humano, modifica-se por completo o quadro do país, abrem-se possibilidades de desenvolvimento muito maiores. Não há país que tenha conseguido se desenvolver sem investir consideravelmente na formação de gente. [...] Esse é o mais importante investimento a fazer, para que haja não só crescimento, mas autêntico desenvolvimento [...] (FURTADO, 2002, p. 19).

$\mathrm{Na}$ segunda metade do século XX, o debate sobre educação e desenvolvimento social tendeu a enfatizar a necessidade de que os países latino-americanos vencessem o atraso "[...] nos investimentos no fator humano, atraso que se traduz em extremas disparidades entre salários de especialistas e do operário comum [...]" (FURTADO, 1999, p.10). Muitos pensadores e técnicos graduados de organismos internacionais ${ }^{7}$ (Gunnar $\mathrm{Myrdal}^{8}$, por exemplo) envolveram-se, na segunda metade do século passado, em debates vigorosos sobre a relação entre educação e desenvolvimento (MYRDAL, 1987; FURTADO, 1962; URQUIDI, 1962; FERNANDES, 1987).

Esse enfoque da habilitação não é novo na América Latina, visto que, desde a década de 1950, ocorreram muitos debates sobre os efeitos que teriam os investimentos na educação no processo de constituição de melhorias sociais e de combate às desigualdades ${ }^{9}$. Tais investimentos seriam, ainda, indicadores de que estaria em curso um projeto capaz de indicar caminhos mais inclusivos.

Mantém-se como certo, ademais, que a extensa agenda do desenvolvimento humano no mundo em desenvolvimento está sem terminar, já que uma quarta parte das pessoas nos países em desenvolvimento ainda não tem satisfeitas as necessidades humanas básicas, carece de níveis mínimos de renda e de serviços sociais decentes [...] (RELATÓRIO DE DESENVOLVIMENTO HUMANO, 1991, p. 39). 
Pode-se afirmar, então, que os RDHs, ao sugerirem que os avanços educacionais são essenciais no combate à pobreza absoluta e ao desemprego, estão retomando um debate que tem sido feito, tanto por acadêmicos quanto por técnicos ${ }^{10}$, na segunda metade do século XX. A UNESCO (Organização das Nações Unidas para a Educação, a Ciência e a Cultura) tem divulgado inúmeros materiais produzidos por assessores e consultores de organismos nacionais e internacionais (Rebeca Grynspan (2010), Bernardo Kliksberg (2002), Jacobo Waiselfisz (1998), Jorge Werthein (1999), Delors (1998), entre outros) que têm destacado o papel da educação no combate às desigualdades e à pobreza.

Celso Furtado argumentava que o problema da pobreza pode e deve ser abordado em seus diversos aspectos. Para ele, são três as dimensões que têm sido mais abordadas por cientistas e técnicos: "1)- A questão da fome endêmica, que está presente, em graus diversos, em todo mundo; 2)- a questão da habitação popular [...]; e 3)- a questão da insuficiência de escolaridade, ue contribui para perpetuar a pobreza.” (FURTADO, 2002, p. 12).

Mesmo antes da publicação dos RDHs, ou seja, antes da década de 1990, os avanços educacionais passam a ser temas recorrentes nos debates e propostas acerca do desenvolvimento social. A formulação do IDH levou, sem dúvida, a uma forte retomada do debate acerca das correlações entre pobreza e deficiências educacionais. Foram retomados também os debates sobre o papel da educação na geração de indivíduos politicamente participativos e capazes de atuar em favor do desenvolvimento humano.

No caso do Brasil, foi publicado, em 1997, um relatório da UNESCO em parceria com o UNICEF (Fundo das Nações Unidas para a Infância) e o Instituto Pólis sobre o programa Bolsa Escola colocado em andamento, na década de 1990, pelo governo do Distrito Federal ${ }^{11}$. Nesse documento intitulado Bolsa Escola: melhoria educacional e redução da pobreza ${ }^{12}$, há uma reflexão sobre educação e pobreza e sobre como a iniciativa denominada Bolsa Escola levava tanto a

[...] uma drástica redução da evasão e repetência escolar, precisamente nos extratos sociais onde estes fenômenos apresentam maior força, [quanto] a uma melhoria substancial no aprendizado e no aproveitamento curricular, pelo incremento da motivação e das aspirações educacionais dos bolsistas [...] (WERTHEIN; KAYAYAN, 1998, p. 14). 
Os organismos internacionais, como UNESCO, UNICEF, PNUD, ONU, passam a incentivar as iniciativas que visavam melhorar o IDH. Todas as ações cuja meta é a associação dos três eixos básicos (educação, longevidade, renda) componentes do Índice do Desenvolvimento Humano ${ }^{13}$ passam a ser valorizadas e destacadas no interior dos RDHs.

\section{OS RDHS E O DEBATE SOBRE A IMPORTÂNCIA DO INVESTIMENTO NA EDUCAÇ̃̃O COMO FORMA DE LUTAR CONTRA A POBREZA E SUAS MAZELAS}

O Relatório do Desenvolvimento Humano de $1990^{14}$ inicia suas incursões pelo tema educacional ressaltando que as taxas de adultos alfabetizados tinham feito, entre 1970 e 1985, progressos consideráveis em alguns países (Chile, México, Tailândia, Jordânia, Botsuana, Zâmbia, Peru, Venezuela) e fracos em outros (Burkina Faso, Sudão, Somália, Mali, Níger, Paquistão, Índia). Mesmo em tais condições, o documento destaca que ocorreu um progresso mundial no número de adultos aptos a ler e a escrever tanto nos países em desenvolvimento como naqueles menos desenvolvidos ${ }^{15}$. Se na década de 1970 a taxa mundial de homens adultos era de 53\%, na de 1980 essa taxa subiu para 71\%. Não se deve deixar de mencionar, ressalta o RDH de 1990 , que, em 1985 , somente $50 \%$ das mulheres eram alfabetizadas.

A tendência nos países desenvolvidos e/ou "em desenvolvimento" é a existência de taxas maiores de alfabetização dos adultos, o que é completamente inverso naqueles países mais pobres. $\mathrm{Na}$ América Latina, por exemplo, as taxas de alfabetização haviam crescido de $72 \%$ para $83 \%$ entre as décadas de 1970 e 1980. O RDH de 1990 traz vários dados comparativos entre as diversas regiões do mundo e detecta que, enquanto na América Latina a taxa de alfabetização entre adultos era de 83\% em 1985, a da Ásia Meridional era somente de $41 \%$. Nos países mais pobres, a taxa média de pessoas alfabetizadas era de 37\%. Todavia, o RDH de 1991 afirma que não se deve pensar que maior renda per capita seja sinônimo de melhorias sociais.

Nenhum melhoramento sustentável do bem-estar humano é possível sem o crescimento. Mas não se pode afirmar que as altas taxas de crescimento econômico se traduzem automaticamente em níveis elevados de desenvolvimento humano. Isto pode ser ou pode não ser. Tudo depende das decisões políticas 
que tomem os países. $\mathrm{O}$ mundo oferece muitos exemplos inquietantes de uma ampla divergência entre os níveis de renda e os de desenvolvimento humano. $\mathrm{O}$ alfabetismo adulto na Arábia Saudita, por exemplo, é inferior ao de Sri Lanka, apesar de que sua renda per capita é 15 vezes superior (RELATÓRIO DE DESENVOLVIMENTO HUMANO, 1991, p. 39).

É interessante observar que Índia, China, Paquistão, Bangladeshe e Indonésia eram mostrados, no RDH de 1990, como muito populosos e possuidores de taxas enormes de analfabetismo e que puxariam para cima as taxas de analfabetismo global. Por isso, os relatórios insistiam, na década de 1990, na correlação estreita entre condição de escolaridade e pobreza. Não obstante estarem em condições diferentes de desenvolvimento econômico, os países acima mencionados encontravam-se em situações semelhantes, no que diz respeito à acessibilidade aos bancos escolares.

Pode-se dizer que dados como os trazidos pelo RDH de 1990 - por exemplo, o progresso lento na redução do analfabetismo naqueles países (a Índia teve taxa de redução anual de 0,97\% entre 1970-1985) com taxas de alfabetização de adultos menor que $50 \%$ - dão uma boa ideia da razão pela qual o economista indiano Amartya Sen vem insistindo no enfoque da habilitação e da geração de capacidades como antídoto contra a pobreza daqueles indivíduos que acabam condenados à perpétua condição de miserabilidade em razão de uma não habilitação que impede que as oportunidades econômicas sejam mais bem distribuídas.

Obviamente, Sen leva muito mais adiante do que levam os RDHs esse debate sobre educação e pobreza. Isso porque ele situa a questão no âmbito das liberdades. Ou seja, "A liberdade é o principal fim e o meio mais importante de desenvolvimento [...]" (SEN, 2001, p. 2). E, nesse caso, a escolarização, a expansão da capacidade e das habilitações proporcionam maior liberdade (econômica e política) de ação dos indivíduos. É essa a discussão que Sen (1988) vem sustentando desde a década de 1980.

Inspirados em discussões dessa natureza, os RDHs de 1991, 1992 e 1993 vão enfatizar o entrelaçamento entre desenvolvimento humano, liberdade humana, liberdade política e participação popular. Tais relatórios partem das discussões empreendidas no primeiro documento do PNUD que traziam dados sobre os avanços e as dificuldades de ampliação do acesso à educação na América Latina, na Ásia e na África. 
A maioria dos pobres o é porque não tem terra, nem capital, nem crédito, nem a oportunidade de desempenhar trabalho decente. Tão pouco tem acesso a serviços sociais adequados. O único remédio a longo prazo é investir nos pobres, particularmente em sua educação e formação e levá-los à corrente do desenvolvimento. A pobreza não deve ser considerada como um resíduo do crescimento econômico. Os governos não deveriam abordar a pobreza depois do crescimento econômico. Deveriam antes adotar modelos de crescimento econômico que incluam como um de seus principais objetivos a eliminação da pobreza $[. . .]^{16}$ (RELATÓRIO DE DESENVOLVIMENTO HUMANO, 1991, p. 40).

Conforme a orientação de todos os demais, também o RDH de 1990 procura trazer à tona os dados que indicam melhorias em várias áreas entre as décadas de 1960 e 1990. No caso da educação, especificamente, há destaque sobre o aumento da escolaridade em várias partes dos países denominados “em desenvolvimento". $\mathrm{Na}$ América latina, por exemplo, segundo os técnicos que prepararam o primeiro $\mathrm{RDH}, 75 \%$ das crianças (meninos e meninas com participação equânime) que viviam nesses países estavam matriculados nas escolas em 1985. Caminhava-se, assim, para a universalização do ensino primário.

O progresso tem sido significativo em todas as regiões. Apesar do estancamento da economia e do rápido crescimento demográfico, a metade dos meninos africanos em idade escolar primária e secundária assiste atualmente a aulas. Ásia, Oriente Médio e África do Norte também mostram uma tendência uniforme de aumento, com uma proporção de escolaridade primária líquida de muito mais que $80 \%$ para os homens. Um maior progresso tem sido obstado por uma baixa escolaridade das mulheres, um desequilíbrio que os futuros programas de educação devem analisar. Na América Latina e no Caribe, a proporção de escolaridade primária líquida alcançou 75\% em 1985, com uma participação igual de meninos e meninas [...] (RELATÓRIO DE DESENVOLVIMENTO HUMANO, 1990, p. 63).

Observe-se que essa constatação, na década de 1990, acerca da disparidade do acesso de meninos e meninas à escola vai estar presente direta ou indiretamente, de modo explícito ou implícito, nas diversas discussões, nos RDHs (2000; 2001; 2003; 2004; 2005; 2009; 2010) posteriores à Declaração do Milênio (2000). Um dos nortes do debate sobre desenvolvimento humano tem sido a geração equânime de oportunidades de emprego, de participação política e de acesso de meninos e meninas e de homens e mulheres a todos os direitos. O RDH de 1995 deu centralidade à igualdade de condições entre 
os sexos. Ele faz uma ampla discussão sobre a persistente desigualdade de gênero, elaborou uma medição de tais disparidades e mostrou como não há possibilidade de avançar rumo ao desenvolvimento humano sem reverter os processos perpetuadores de desigualdades entre homens e mulheres (RELATÓRIO DE DESENVOLVIMENTO HUMANO, 1995).

O RDH de 1990 dá destaque ao fato de que, na América Latina e na Ásia, tanto nos países já industrializados, há algum tempo, como nos países de industrialização mais recente, as matrículas nos níveis primário, secundário e terciário têm sido quase equivalentes. O documento demonstra, outrossim, a diferença gritante, quanto ao acesso à educação terciária, nos países "em desenvolvimento" e nos "menos desenvolvidos”. Em 1990, “[...] nos países menos desenvolvidos as matrículas em instituições de ensino de terceiro nível são de 1\% para as mulheres e de 4\% para os homens [...]" (RELATÓRIO DE DESENVOLVIMENTO HUMANO, 1990, p. 63).

Um dos desafios apontados pelos relatórios é que o crescente acesso das pessoas aos serviços educativos leva a grandes desafios, pois os recursos, nos países "em desenvolvimento", têm de ser partilhados com um número crescente de indivíduos que passam a frequentar os bancos escolares. O RDH de 1990 menciona, além disso, que o crescimento demográfico dessas regiões desafia a distribuição dos recursos que levam a melhorias sociais e ao bem-estar.

Para a maioria dos países em desenvolvimento, o desenvolvimento humano constitui um triplo desafio. Devem ampliar as oportunidades de desenvolvimento para um número crescente de pessoas, devem melhorar os níveis de vida, e, em geral, devem lograr mais com menos para fazer frente aos dois primeiros objetivos apesar de permanecerem estancados ou diminuídos os seus recursos. (RELATÓRIO DE DESENVOLVIMENTO HUMANO, 1990, p. 64).

O primeiro relatório do PNUD/ONU ressaltava, no entanto, que havia grandes riscos de ocorrerem "[...] graves transtornos no desenvolvimento humano [...]” (RELATÓRIO DE DESENVOLVIMENTO HUMANO, 1990, p. 65). As crises, as dívidas externas, as dificuldades nas relações comercias, as disparidades econômicas no mercado mundial estariam impondo cada vez mais percalços para os investimentos que propiciam melhorias sociais capazes de fortalecer as capacidades humanas. Esta noção é chave para o debate proposto pelos RDHs, já que “[...] pessoas 
qualificadas, saudáveis e escolarizadas se encontram em melhores condições que outras para dirigir sua própria vida. Geralmente é mais provável que encontrem empregos e ganhem melhores salários [...]" (RELATÓRIO DE DESENVOLVIMENTO HUMANO, 1990, p. 66).O relatório de 1991 faz ainda a seguinte afirmação: "Uma força laboral saudável, bem alimentada, bem educada e capacitada é a melhor base para o crescimento [...]" (RELATÓRIO DE DESENVOLVIMENTO HUMANO, 1991, p. 41).

O rompimento com a condição de pobreza e com a condição de inviabilização econômica, política e social está, segundo os relatórios, ligado umbilicalmente ao desenvolvimento das capacidades humanas. "A pessoa instruída também pode contribuir mais para o avanço da cultura, da ciência e da tecnologia [...]" (RELATÓRIO DE DESENVOLVIMENTO HUMANO, 1990, p. 66). Segundo o documento das Nações Unidas, a expansão das capacidades e das habilidades através da "[...] melhora da qualidade e da aplicabilidade dos conhecimentos dos estudantes [...]” (RELATÓRIO DE DESENVOLVIMENTO HUMANO, 1990, p. 64) levará à expansão das oportunidades de rendas não somente no trabalho formal, mas também nas atividades informais.

O RDH de 1990 constata que há um aumento expressivo, desde a década de 1980, do emprego no setor informal. Na África, o setor informal gerou $75 \%$ dos novos empregos entre 1980 e 1985 e o setor formal somente $6 \%$. Na América Latina, houve também um crescimento maior do trabalho informal. Ou seja, $56 \%$ dos novos postos de trabalho ocorreram neste setor. O relatório reforça, então, que essas atividades necessitam de mais apoio político e econômico dos governantes. O documento tenta demonstrar que o problema não está exatamente na condição de informalidade, mas sim na não vigência de um desenvolvimento sustentável que reinvista continuamente nos seres humanos (RELATÓRIO DE DESENVOLVIMENTO HUMANO, 1990, p. 66).

Não há críticas, no interior do RDH de 1990, às condições de informalidade que geram precariedade de direitos e todas as mazelas dela derivadas. Para este relatório, o que proporciona a existência e o aumento dos trabalhos informais precários e de riscos são os baixos investimentos na formação educacional. "A capacitação, junto com a educação geral, promove o uso mais produtivo das aptidões humanas [...]" (RELATÓRIO DE DESENVOLVIMENTO HUMANO, 1990, p. 67). 
O documento do PNUD enfatiza que, quando se trabalha para os outros ou por conta própria, o que faz a grande diferença é o grau de instrução. O grau de conhecimento obtido potencializa a renda e as oportunidades não somente econômicas, mas também de participação política (RELATÓRIO DE DESENVOLVIMENTO HUMANO, 1993).

Os agricultores da república da Coreia, Malásia e Tailândia, utilizando a tecnologia moderna, produziram 3\% mais por cada ano adicional de educação recebida. E o maior nível de educação dos agricultores do Punjab hindu explica, em parte, porque sua produtividade é maior que a dos agricultores do Punjab paquistanês. Assim, o investimento em capital humano aumenta a produtividade dos indivíduos e suas possibilidades de emprego, acrescentando potencial para o crescimento econômico. Obviamente, se a educação não cria as destrezas requeridas pela sociedade, pode conduzir ao desemprego as pessoas que têm recebido educação e a um considerável desperdício dos talentos humanos [...] (RELATÓRIO DE DESENVOLVIMENTO HUMANO, 1990, p. 68).

Alícia Ziccardi, no texto Las ciudades y la cuestión social, afirma que na América Latina há uma enorme variedade de atividades informais que vão desde o trabalho por conta própria numa pequena empresa até o de vendedor ambulante. O que caracteriza esse grupo é que

[...] são situações que deixam o trabalhador à margem do cumprimento de direitos sociais pactuados por organizações sindicais e/ou estabelecidos nas leis laborais. A contrapartida é transformá-los em um número maior de demandantes de serviços sociais públicos, e como a tendência é reduzir os gastos governamentais, isto implica na deterioração da qualidade dos mesmo [...] (ZICCARDI, 2002, p. 92).

$\mathrm{Na}$ verdade, o que os RDHs estão a defender é um apoio do poder público para aqueles que exercem tais atividades. $\mathrm{O}$ investimento em melhorias educacionais deveria, então, ser a grande preocupação dos diversos governantes, visto que isso possibilitaria uma atuação, tanto profissional quanto política, diferenciada da atuação daqueles que estão nesse tipo de mercado de trabalho. A contrapartida do Estado seria o investimento educacional que possibilitaria formar nos indivíduos a disposição para lutar, estando ou não no mercado informal, por seus direitos sociais. 


\section{OS RDHS E OS AVANCִOS EDUCACIONAIS COMO ANTÍDOTOS CONTRA A POBREZA, A DISCRIMINAÇÃO E A NÃO PARTICIPAC̣ÃO POLÍTICA}

Os documentos do PNUD editados desde a década de 1990 têm ressaltado insistentemente que a escolarização é o caminho mais adequado para criar nos indivíduos capacidades não somente profissionais, mas também políticas. Há, no interior dos relatórios, um estreitamente de foco na necessidade de que os governantes invistam em políticas educacionais cada vez mais ampliadas e capazes de habilitar os indivíduos para uma participação política que consiga levar as suas demandas para a esfera pública. O desenvolvimento humano, dizem os documentos, está estreitamente ligado à diminuição paulatina da privação humana. $\mathrm{O}$ investimento na educação tende a ajudar a reduzir as condições tanto de miserabilidade quanto de impotência. Rebecca Grynspan (2010), diretora regional para a América Latina do PNUD, tem demonstrado que a combinação de privação e impotência é um fator que debilita a luta contra a pobreza, realidade que, de forma singularizada pela natureza propositiva dos relatórios, tem estado presente no interior dos RDHs.

Existe “[...] privação, porque os indivíduos não dispõem de rendas nem de ativos suficientes para satisfazer suas necessidades materiais mais elementares [...]" (ZICCARDI, 2002, p. 96).Existe, ainda, "[...] impotência porque [eles] não possuem nem a organização, nem o acesso ao poder político para mudar a situação [...]" (ZICCARDI, 2002, p. 96). É justamente essa constatação que se encontra sobejamente demonstrada no interior dos RDHs da década de 1990 e de 2000. O investimento na educação ganha supremacia na formulação de propostas para combater simultaneamente a privação e a impotência. Entende-se que esta última resulta da falta de expectativa tanto de obter emprego e renda quanto de encontrar algum meio de construir processos reivindicativos.

Tendo como base os dados de que as taxas de alfabetização de adultos aumentaram de 46\% para 60\% entre 1970 e 1985 nos países em desenvolvimento (tais como: Chile, México, Brasil, Costa Rica, entre outros), mas que mesmo assim 1 milhão de pessoas adultas continuam sendo analfabetas e 300 milhões de crianças não vão à escola primária ou secundária, o RDH de 1991 destacava a necessidade de que os países investissem numa escolarização apta a formar capacidades e habilidades diretamente voltadas 
para o desenvolvimento humano. Lena Lavinas, ao discutir o plano do governo $^{17}$ federal elaborado para erradicar a miséria, afirma que é preciso ter ciência de que “[...] não se convertem automaticamente bens primários como educação elementar ou outras acessibilidades em capacidades e habilidades para viver autônoma e livremente [...]" (LAVINAS, 2011, p. 3).

As proposições dos RDHs demonstram que há ciência disso, tanto que se concebem os avanços educacionais como parte de um amplo processo de mudança das condições de privação e impotência. Lavinas ${ }^{18}$, porém, diz que a educação só se transforma em capacidade e habilidade se houver algumas garantias institucionais favorecedoras disso. É com respeito a isso que os relatórios do PNUD se deparam com algumas dificuldades, pois, no intuito de abranger um conjunto enorme de países designados como "em desenvolvimento" ou "menos desenvolvidos", não é possível que os documentos levem em conta as especificidades institucionais de cada país e verifiquem, portanto, até que ponto é possível transformar a educação em habilidades e capacidades econômicas e políticas.

Observam-se, no interior dos RDHs de 1991, algumas indicações sobre o modo como os Estados devem proceder para garantir a expansão das habilidades e capacidades.

Pois assim, o desenvolvimento amplia as oportunidades dos indivíduos, sempre e quando se cumpram duas condições. Em primeiro lugar, a ampliação das oportunidades de um indivíduo ou de um setor não deve restringir as oportunidades de outros. É necessário, então, que as relações humanas sejam equitativas. Em segundo lugar, ao melhorar a vida da geração presente não se devem obstar as oportunidades das gerações futuras, ou seja, o processo de desenvolvimento deve ser sustentável [...] (RELATÓRIO DE DESENVOLVIMENTO HUMANO, 1991, p. 42).

O RDH de 1991, por exemplo, ao sugerir diversas políticas para expandir a luta contra a privação humana - a qual se expressa na baixa esperança de vida ao nascer, na não garantia de acesso a serviços de saúde, na desnutrição, no analfabetismo de jovens e adultos, na ausência de renda suficiente para sair da pobreza absoluta, no não acesso a serviços sanitários e de saneamento - acaba por fazer considerações genéricas sobre as possibilidades institucionais que têm os países das mais diferentes regiões de fazer investimentos que apontem para a expansão das capacidades e habilidades. 
No livro El valor de la democracia, Amartya Sen assevera que a democratização é condição fundamental para tornar efetiva a participação de indivíduos e grupos nos processos de desenvolvimento humano. Segundo ele, várias pesquisas têm demonstrado que as políticas eficazes na área econômica dependem de um crescente aumento da escolarização, da alfabetização e da ampliação das diversas oportunidades sociais "[...] que ampliam a participação de todos [e não somente de alguns] no processo de expansão econômica [...]" (SEN, 2006, p. 65). O cientista indiano, inspirador do IDH, faz essas afirmações em vista de algo destacado pelo RDH de 1991.

A educação também varia com a renda, [o que ocorre] em proporções, às vezes, estarrecedoras. Em algumas aldeias da Índia, a taxa de alfabetização para as castas superiores, os Brahmins, era de $90 \%$, enquanto que para as castas inferiores apenas alcançava 10\% [...] (RELATÓRIO DE DESENVOLVIMENTO HUMANO, 1991, p. 68).

Os debates sobre a educação nos RDHs têm o mérito de revelar, nos debates sobre a educação, que o Índice de Desenvolvimento Humano Feminino (IDHF) é muito menor que o Índice de Desenvolvimento Humano Masculino (IDHM). Há países, como o Kenia, Myanmar e Singapura que, em 1991, o IDHF não atingia 1/3 do IDHM.

A proporção de matrículas femininas em estabelecimentos de educação secundária nos países em desenvolvimento [...] é apenas a metade. Em muitos países, a taxa de alfabetização feminina mantém-se baixa. No sul da Ásia, [tal taxa] alcança somente a metade [da] dos homens. E as cifras [para a alfabetização das mulheres] são ainda piores em outros países, como no Afeganistão (24\%), Sudão (25\%), Serra Leoa (30\%) e Nepal (32\%) [...] (RELATÓRIO DE DESENVOLVIMENTO HUMANO, 1991, p. 69).

Os documentos do PNUD, ao longo da década de 1990, têm asseverado que em muitas partes do mundo as mulheres possuem muito menos possibilidade de desenvolver habilidades e capacidades garantidoras de maior autonomia. Há, até mesmo no RDH de 1990, a constatação de que os meninos são mais bem nutridos que as meninas e também recebem mais assistência médica. Ao se limitar a essas mulheres o acesso à educação, a alimentos e ao atendimento médico ${ }^{19}$ reduz-se-lhes o desenvolvimento humano e elas acabam por não ter como desfrutar de qualquer autonomia 
pessoal e/ou profissional e não tendo sequer direito, muitas vezes, a uma identidade própria.

As discriminações contra as meninas iniciam, em várias partes do mundo, muito cedo (RELATÓRIO DE DESENVOLVIMENTO HUMANO, 1990, p. 75). Portanto, o acesso escolar acaba sendo inteiramente inviabilizado e o resultado disso são outras formas de exclusões e de desigualdades tanto em renda quanto em participação política. As diversas diferenças entre homens e mulheres são reforçadas pela educação; por isso, a Declaração do Milênio (2000) estabelece que um dos seus principais objetivos é a universalização do ensino básico para meninos e meninas. No limiar do século XXI, as Nações Unidas já haviam reunido, nos 10 relatórios da década de 1990, materiais demonstrando o quanto se ampliavam as diferenças entre os sexos em razão da negligência da sociedade e do Estado em diversas áreas.

Em 16 países em desenvolvimento, a matrícula escolar feminina a nível primário é mais de um terço menor que a dos homens. E 17 países registram matrículas de mulheres na educação secundária numa proporção equivalente a menos da metade das matrículas de homens [...] (RELATÓRIO DE DESENVOLVIMENTO HUMANO, 1990, p. 77).

No que diz respeito aos indicadores de desenvolvimento humano, os RDHs, da década de 1990, já destacavam a necessidade de criar índices específicos para mensurar até que ponto persistiam, no final do século XX, os avanços diferenciados entre homens e mulheres. O RDH de 1995 trazia o IDM (Indicador de Desenvolvimento relacionado com a mulher). $\mathrm{Na}$ área da educação, esse indicador era apontado como essencial, pois assim seria possível verificar até que ponto estavam ou não ocorrendo diminuição nas diversas formas de desigualdades.

Duas desigualdades, reforçadas pelo não acesso igualitário à educação, são, dizem os RDHs, a de renda e a de participação política. São mencionadas repetidamente as diferenças de renda entre homens e mulheres e a penúria e os trabalhos extremamente precários a que estas, tornadas arrimo de família, estão submetidas. Aquilo para o que os documentos do PNUD chamam a atenção é que em "[...] nenhuma sociedade as mulheres desfrutam das mesmas oportunidades que os homens [...]” (RELATÓRIO DE DESENVOLVIMENTO HUMANO, 1995, p. 2), todavia essa situação 
tende a se agravar acentuadamente em algumas partes do planeta em que há discriminações institucionalizadas contra as mulheres. O RDH de 1995 afirmava que era possível constatar avanços, em favor das mulheres, no desenvolvimento de políticas educacionais, das quais resultavam maior esperança de vida, diminuição das taxas de fecundidade, maior rendimento, maior autonomia e, até mesmo, possibilidades delas participarem “[...] em todas as formas de vida da comunidade [...]" (RELATÓRIO DE DESENVOLVIMENTO HUMANO, 1993, p. 25) a que pertençam. No que diz respeito à situação política “[...] significa a liberdade de eleger e cambiar o governo em todos os níveis, desde o palácio presidencial até o conselho da aldeia [...]" (RELATÓRIO DE DESENVOLVIMENTO HUMANO, 1993, p. 25).

Todavia, deve-se destacar que o relatório de 1993 destacava que a participação política em geral (de homens e mulheres) só poderia advir de investimentos na geração de habilidades e capacidades, as quais não são tidas somente como capazes de tornar as pessoas aptas a obter rendimentos mais elevados, mas também a participar cada vez mais efetivamente da vida política. No entanto, para que isso ocorra, é necessário que o gasto público priorize aquelas áreas que alavanquem o desenvolvimento humano. A educação é uma delas. Mas também é fundamental que os governantes e lideranças políticas, de modo geral, envidem esforços no aprimoramento de uma forma de democratização que reforce mais e mais o papel da sociedade civil e das organizações populares no processo de governança ${ }^{20}$.

"O desenvolvimento humano sublinha a necessidade de investir nas capacidades humanas e depois assegurar que essas capacidades se utilizem em benefício de todos [...]” (RELATÓRIO DE DESENVOLVIMENTO HUMANO, 1993, p. 26). Maior participação potencializa o aproveitamento das capacidades e das habilidades. Daí haver, nos relatórios, a crença de que há forte relação entre melhoria dos níveis educacionais e avanços nos processos participativos favorecedores do aprofundamento da democracia, a qual abarca vários aspectos, entre os quais estão:

Garantia de direitos humanos, incluídas as liberdades de expressão e de associação; império do direito; eleições livres e imparciais; um sistema multipartidarista [e] uma transição ordenada de um governo a outro [... $]^{21}$ (RELATÓRIO DE DESENVOLVIMENTO HUMANO, 1993, p. 28) 
e ainda a plena participação da sociedade civil. $\mathrm{O}$ acesso universalizado à educação leva, então, segundo os documentos analisados, ao aumento da participação política, da participação na vida econômica e da participação social e cultural.

\section{CONSIDERAÇ̃̃ES FINAIS}

Os debates contidos nos RDHs são a sistematização de propostas de ações em diversos campos da vida social. Todos os documentos têm como núcleo central a necessidade de encontrar formas de construção de práticas e procedimentos que possibilitem avanços nos indicadores de renda, longevidade e educação. Essas três dimensões entrelaçam-se no processo de desenvolvimento humano.

Neste artigo, tentou-se demonstrar que os avanços educacionais postos como metas aos países "em desenvolvimento" e "menos desenvolvidos" aparecem, no interior dos documentos do PNUD, como essencialmente definidores de melhorias nas condições de renda e de longevidade. Fica, então, evidenciado que a dimensão educacional ganha, assim, uma posição de destaque nas proposições contidas nos RDHs, uma vez que impulsionar as condições de rendimento, de nutrição e de saúde implica desenvolver capacidades e habilidades. Não se está afirmando que os relatórios não se dediquem, a contento, aos problemas relacionados ao não crescimento econômico, às dificuldades de democratização, à falta de liberdades, à não garantia de direitos, aos efeitos nefastos da urbanização precária, entre outros. Todos eles são fartamente discutidos ao longo das centenas de páginas dos 20 relatórios anuais publicados entre 1990 e 2010. Está-se, sim, afirmando que os desafios educacionais, vindos à tona nos RDHs, interpenetram-se e acabam por se enlaçar a todas as demais propostas que visam construir avanços sociais, políticos e econômicos.

Sendo os RDHs a sistematização de muitas propostas que objetivam sugerir aos Estados nacionais, aos governantes e às lideranças da sociedade civil ações e procedimentos capazes de reverter a pobreza absoluta e a miserabilidade, têm-se neles dados que dão a dimensão tanto da complexidade e profundidade dos desafios presentes no mundo, hoje, quanto as (im) possibilidades suscitadas pelas tentativas de um organismo internacional, como as Nações Unidas, de condensar, em propostas efetivas, as sugestões 
geradoras de novas formas de intervir na área educacional em países com situações e percursos históricos muito diversos e singulares.

Os RDHs trazem propostas amplas, às vezes até mesmo genéricas, na área educacional. Estas não têm como contemplar as inúmeras especificidades regionais ou locais, todavia, há tentativas de levar em conta, ao menos algumas de suas singularidades, ao se proporem ações que devam partir dos patamares vigentes nos continentes africano, asiático e latino-americano. No caso desse último, é considerado o fato de que não há problemas graves no que diz respeito à universalização do ensino para meninos e meninas. Nos dois outros continentes, há ainda, no limiar do século XXI, muitos impedimentos para tal universalização. No que concerne às taxas de alfabetização, há também percentuais muito distintos entre os países africanos e os latino-americanos, bem como diferenças gritantes no que se refere à superação das muitas dificuldades nas áreas educacionais. Os índices de melhorias e avanços são bastante diferenciados nas diversas regiões do mundo.

Em vista disso pode-se perguntar: Em que proporção são (in) viáveis as propostas na área da educação que estão sistematizadas no interior dos RDHs? É evidente que cabem inúmeras indagações sobre se são, ou não, factíveis. Elas são, porém, relevantes, não por serem a solução para todos os males e problemas educacionais, mas sim por condensarem debates e desafios globais que são, como diz Norbert Elias (1994, p. 138), “[...] sintomas de um processo que se move em determinadas direções e $[\ldots]$ abrange toda a humanidade [...]".

Tomaram-se, neste artigo, as propostas das Nações Unidas, na área da educação, como uma busca de respostas e soluções para inúmeros problemas com que se deparam os povos mais pobres do planeta. Assim, tais propostas fazem parte de um processo que torna possível aprender como lidar com os velhos e os novos desafios postos à educação num mundo cada vez mais interdependente. Conforme insiste Norbert Elias (1994), pela primeira vez na história da humanidade, a integração da humanidade é de fato uma realidade. É, em tais condições, que esta organização internacional vem dando alguns passos para promover ações por parte de Estados, governantes, lideranças da sociedade civil, educadores, administradores escolares, pesquisadores, intelectuais, etc. Tais ações buscam soluções para os problemas educacionais que negam a muitos jovens e crianças, em várias partes do mundo, oportunidades mais 
justas em muitas áreas, não somente nas profissionais, mas também naquelas relacionadas ao acesso ao conhecimento de modo mais amplo.

Não há dúvida de que as metas educacionais postas pelos RDHs encontram-se desafiadas também pelo processo de individualização atual, do qual muitas vezes muito se aproximam ao sugerir ações que encarreguem os próprios indivíduos das soluções, conforme diz Bauman (2001), de problemas sistêmicos. Há, nos relatórios, muitos apelos às ações individuais (através de organizações voluntárias, ONGs e associações de diversas naturezas) que lançam dúvidas sobre a efetividade das soluções propostas.

Se a sociedade moderna esteve, conforme assinala Bauman (2001), Elias (1994) e Beck (2003), desde os seus primórdios, assentada na individualização, não se deve esquecer que esta última tinha características distintas há 100 anos, posto que ela era sinônima tanto da tentativa de rompimento com uma teia de dependências comunitárias e familiares quanto da possibilidade de geração de novas interdependências baseadas nas relações advindas do crescente processo de industrialização e urbanização. A individualização atual expressa, fundamentalmente, a atribuição de responsabilidades aos indivíduos para que encontrem respostas para todos os problemas que os acometem. Reitera-se, às vezes, a dificuldade de que as ações sejam transpostas do âmbito individual para o âmbito coletivo, das soluções isoladas para as soluções públicas.

Investigar até que ponto as propostas no campo educacional aproximam-se ou não das perspectivas individualizantes demanda um empenho mais eficaz em conhecer a relação entre educação e geração de capacidades, habilidades e oportunidades. Isso será feito num outro artigo que deverá partir do pressuposto de que há uma crescente

[...] lacuna entre a individualidade como destino [aquela que insiste que, no mundo atual, o indivíduo, isoladamente, é que deve buscar saídas para todos os seus problemas] e a individualidade como capacidade [aquela que pressupõe que o indivíduo vai, aos poucos, se capacitando e se habilitando a buscar soluções coletivas para os problemas econômicos, políticos e sociais que o atingem] (BAUMAN, 2008, p. 65). 


\section{REFERÊNCIAS}

AFEGÃO é morto por lecionar para meninas. Folha de São Paulo, São Paulo, 26 maio 2011. Caderno A. p. 22.

AZEVEDO, F. Sociologia educacional. São Paulo: Melhoramentos, 1958a.

AZEVEDO, F. A educação e seus problemas. São Paulo: Melhoramentos, 1958b. Tomo I

BAUMAN, Z. Modernidade líquida. Rio de Janeiro: Jorge Zahar, 2001.

BAUMAN, Z. A sociedade individualizada. Rio de Janeiro: Jorge Zahar, 2008.

BECK, U. Liberdade ou capitalismo. São Paulo: Unesp, 2003.

BOMFIM, M. A América Latina: males de origem. Rio de Janeiro: TopBooks, 1993.

BUARQUE, C. A revolução das prioridades: da modernidade técnica à modernidade ética. São Paulo: Paz e Terra, 1994.

COMISSÃO ECONÔMICA PARA A AMÉRICA LATINA E O CARIBE - CEPAL. El desarrollo social de américa latina en la postguerra. Buenos Aires: Solar, Hachette, 1963. Documento E/CN.i2/660, apresentado pela Cepal al décimo Período de Sesiones, Mar Del Plata. COMISSÃO ECONÔMICA PARA A AMÉRICA LATINA E O CARIBE - CEPAL. Objetivos de Desenvolvimento do Milênio: uma visão a partir da América Latina e do Caribe. CEPAL/ONU, 2005. Folha Informativa. Disponível em: <www.pnud.org.br/arquivos/ ODM-Cepal>. Acesso em: 18 jun. 2005.

DELORS, J. (Org.). Educação um tesouro a descobrir. São Paulo: Cortez; Brasília: Unesco, 1998. DUBET, F. As desigualdades multiplicadas. Ijuí: Unijui, 2003.

ELIAS, N. A sociedade dos indivíduos. Rio de Janeiro: Jorge Zahar, 1994.

ESPING-ANDERSEN, G. Um Estado de bem-estar social para o século XXI. In: GIDDENS, A. (Org.). O debate global sobre a terceira via. São Paulo: Unesp, 2007. p. 193-224. FERNANDES, F. O dilema educacional brasileiro. In: PEREIRA, L.; FORACCHI, M. Educação e sociedade. São Paulo: Nacional, 1987. p. 414-444.

FURTADO, C. A pré-revolução brasileira. Rio de Janeiro: Fundo de Cultura, 1962.

FURTADO, C. Prefácio à nova economia política. Rio de Janeiro: Paz e Terra, 1977.

FURTADO, C. A reconstrução do Brasil. Praga, São Paulo, n. 8, p. 9-13, ago. 1999.

FURTADO, C. Em busca de novo modelo. Rio de Janeiro: Paz e Terra, 2002.

GRYNSPAN, R. Desenvolvimento, crescimento e superação da pobreza: desafios impostos pela crise internacional. In: COELHO, M. F. P.; TAPAJÓS, L. M. S.; RODRIGUES, M. Políticas sociais para o desenvolvimento: superar a pobreza e promover a inclusão: simpósio internacional sobre desenvolvimento social. Brasília: MDS, 2010. p. 27-44.

INFANTE, A. Uganda aposta na educação e salta no IDH. Boletim diário do PNUD, 08 set. 2005. Disponível em: <http://www.pnud.org.br/pobreza_desigualdade/reportagens/ index.php?01=1454\&lay>. Acesso em: 9 set. 2005.

KLIKSBERG, B. Mitos e realidades em educação. In: KLIKSBERG, B. Desigualdade na América Latina: o debate adiado. São Paulo: Cortez/Unesco, 2002. p. 49-61.

KLIKSBERG, B. O desafio da exclusão. São Paulo: Fundap, 1997.

JESSOP, B. State theory: putting capitalist states in their place. University Park: The Pennsylvania State Press, 1990.

JUDT, T. O mal ronda a terra: um tratado sobre as insatisfações do presente. Rio de Janeiro: Objetiva, 2011. 
LAVINAS, L. Erradicação da miséria, bons auspícios. Folha de São Paulo, São Paulo, 21 jun. 2011. Caderno 1. p. 3.

MYRDAL, G. O mundo subdesenvolvido. In: PEREIRA, L.; FORACCHI, M. Educação e sociedade. São Paulo: Nacional, 1987. p. 364-367.

NAÇÕES UNIDAS. Declaração do Milênio. New York: Nações Unidas, 2000. Disponível em: <www.undp.org/hdr2001>. Acesso em: 20 mar. 2011.

PARADAS, M. B. Educação e pobreza: uma relação conflitiva. In: ZICCARDI, A. (Org.). Pobreza, desigualdad socialy ciudadania. Buenos Aires: Clacso, 2002. p. 65-81.

PEREIRA, L; FORRACHI, M. (Orgs.) Educação e sociedade. São Paulo: Nacional, 1987. PROGRAMA DAS NAÇÕES UNIDAS PARA O DESENVOLVIMENTO - PNUD. Desenvolvimento humano e IDH. PNUD, 2001. Primeira página. Disponível em: <http:// www.pnud.org.br/idh>. Acesso em: 18 ago. 2010.

RELATÓRIO DE DESENVOLVIMENTO HUMANO - RDH. Direitos Humanos e Desenvolvimento Humano. PNUD/ONU, 2000. Disponível em: <http://hdr.undp.org/en/ reports/global/hdr2000/chapters/spanish/>. Acesso em: 11 jan. 2011

RELATÓRIO DE DESENVOLVIMENTO HUMANO - RDH. Definição e medição do desenvolvimento bumano. PNUD/ONU, 1990. Disponível em: <http://hdr.undp.org/en/ reports/global/hdr1990>. Acesso em: 02 jun. 2011.

RELATÓRIO DE DESENVOLVIMENTO HUMANO - RDH. Financiamento do Desenvolvimento Humano. PNUD/ONU, 1991. Disponível em: <http://hdr.undp.org/en/ reports/global/hdr1991> Acesso em: 02 jul. 2011.

RELATÓRIO DE DESENVOLVIMENTO HUMANO - RDH. Uma nova visão sobre o desenvolvimento humano internacional. PNUD/ONU, 1992. Disponível em: < http://hdr.undp. org/en/reports/global/hdr1992>. Acesso em: 22 jun. 2011.

RELATÓRIO DE DESENVOLVIMENTO HUMANO - RDH. Participação popular. PNUD/ONU, 1993. Disponível em: < http://hdr.undp.org/en/reports/global/hdr1993>. Acesso em: 02 mar. 2011.

RELATÓRIO DE DESENVOLVIMENTO HUMANO - RDH. La revolución hacia la igualdade en la condición de los sexos. PNUD/ONU, 1995. Disponível em: < http://hdr.undp. org/en/reports/global/hdr1990>. Acesso em: 02 jul. 2011.

RELATÓRIO DE DESENVOLVIMENTO HUMANO - RDH. Fazendo as novas tecnologias trabalhar para o desenvolvimento humano. PNUD/ONU, 2001. Disponível em: < http://www. pnud.org.br/rdh> Acesso em: 11 jan. 2011.

RELATÓRIO DE DESENVOLVIMENTO HUMANO - RDH. Aprofundar a democracia num mundo fragmentado. PNUD/ONU, 2002. Disponível em: <http://www.pnud.org.br/ rdh>. Acesso em: 02 dez. 2010.

RELATÓRIO DE DESENVOLVIMENTO HUMANO - RDH. Um pacto entre nações para eliminar a pobreza humana. PNUD/ONU, 2003. Disponível em: <http://www.pnud. org.br/rdh> Acesso em: 11 jan. 2011.

RELATÓRIO DE DESENVOLVIMENTO HUMANO - RDH. Um programa para a cúpula munidial sobre Desenvolvimento social. PNUD/ONU, 2004. Disponível em: < http:// www.pnud.org.br>. Acesso em: 09 set. 2010. 
RELATÓRIO DE DESENVOLVIMENTO HUMANO - RDH. Cooperação internacional numa encruzilhada. PNUD/ONU, 2005. Disponível em: <http://www.pnud.org.br> Acesso em: 08 set. 2010.

RELATÓRIO DE DESENVOLVIMENTO HUMANO - RDH. Superando barreiras: mobilidade e desenvolvimento humano. PNUD/ONU, 2009. Disponível em: <http:// hdr.undp.org/en/reports/global/hdr2009>. Acesso em: 02 jun. 2011.

RELATÓRIO DE DESENVOLVIMENTO HUMANO - RDH. A verdadeira riqueza das nações: caminhos do desenvolvimento humano. PNUD/ONU, 2010. Disponível em: <http://hdr.undp.org/en/reports/global/hdr2010>. Acesso em: 02 jun. 2011.

REZENDE, M. J. As metas socioeconômicas denominadas Objetivos de Desenvolvimento do Milênio da ONU: os percalços de um projeto de combate á pobreza absoluta e à exclusão social. Convergência, Toluca, v. 14, n. 43, p. 169-209, 2007a.

REZENDE, M. J. As novas tecnologias podem ser coadjuvantes no processo de cumprimento dos Objetivos de Desenvolvimento do Milênio da ONU? Investigación \& Desarrollo, Colômbia, v. 15, n. 2, p. 289-318, 2007 b.

REZENDE, M. J. As múltiplas implicações da efetivação da democracia hoje: os desafios vindos à tona no RDH, de 2002, das Nações Unidas. Reflexión Política, Bucaramanga, n. 20, p. 29-43, dez. 2008a.

REZENDE, M. J. As nações Unidas e a questão democrática hoje. Política y cultura, México, n. 30, p. 91-118, 2008b.

REZENDE, M. J. Democracia e diversidade cultural: os desafios apontados no RDH/ PNUD/ONU, de 2004. Cuadernos Interculturales, Valparaíso, n. 13, p. 155-179, 2009.

REZENDE, M. J. Desigualdades, exclusões e engenharia social: a proposta do RDH/ PNUD/ONU, de 2004. Investigación \& Desarrollo, Colômbia, v. 18, n. 2, 2010.

RHODES, R. Understanding governance. Miton Keynes: Open Universithy Press, 1997.

SEN, A. Desenvolvimento como liberdade. São Paulo: Cia das Letras, 2005.

SEN, A. Entrevista programa Roda Vida da TV Cultura. 2001. Memória Roda Vida. Disponível em: <http://www.rodaviva.fapesp.br>. Acesso em: 2 jan. 2011.

SEN, A. Racionalidade, interesse e identidade. In: FOXLEY, A.; MCPHERSON, M.; O’DONNELL, G. (Orgs.). Desenvolvimento, política e aspiração social. São Paulo: Vértice, 1988. SEN, A. El valor de la democracia. Madrid: El Viejo Topo, 2006.

SMITH, A. Governança de múltiplos níveis: o que é e como pode ser estudado. In: PETERS, G.; PIERRE, J. (Orgs.) Administração pública. São Paulo: Unesp/ENAP, 2010.

TEIXEIRA, A. A educação escolar no Brasil. In: PEREIRA, L.; FORACCHI, M. Educação e sociedade. São Paulo, Nacional, 1987. p. 388-413.

URQUIDI, V. Viabilidad econômica de América Latina. México: Fondo de Cutura, 1962.

WAISELFISZ, J. J. Bolsa escola: melhoria educacional e redução da pobreza. Brasília: Unesco, 1998.

WERTHEIN, J. Educação, trabalho e desemprego: novos tempos, novas perspectivas. Brasília: Unesco, 1999.

WERTHEIN, J.; KAYAYAN, A. Introdução. In: WAISELFISZ, J. J. Bolsa escola: melhoria educacional e redução da pobreza. Brasília: Unesco, 1998. p. 13-14.

ZICCARDI, A. Las ciudades y la cuestión social. In: ZICCARDI, A. (Org.). Pobreza, desigualdad social y ciudadania. Buenos Aires: Clacso, 2002. p. 85-126. 


\section{NOTAS}

${ }^{1}$ São oito os Objetivos de Desenvolvimento do Milênio. São eles: 1) Eliminar a extrema pobreza e a fome; 2) Universalizar o ensino básico; 3) Buscar a igualdade de gênero; 4) Diminuir a mortalidade de crianças; 5) Promover a saúde materna; 6) Combater as doenças evitáveis e transmissíveis; 7) Investir na geração de sustentabilidade ambiental; 8) Investir na geração de uma parceria mundial para o desenvolvimento.

${ }^{2}$ O objetivo n.2 (Atingir o ensino básico universal) da Declaração do Milênio tem como meta "[...] garantir, para o ano 2015, que os meninos e meninas de todo mundo possam concluir um ciclo completo do ensino fundamental [...]” (COMISSÃO ECONÔMICA PARA A AMÉRICA LATINA E O CARIBE, 2005, p. 3). Todavia, mesmo no ano de 2011 têm vindo à tona casos extremos - como o de um diretor (Kham Mohammad) de escola, afegão, que foi assassinado por lecionar para meninas (AFEGÃO..., 2011, p. 22) - que elucidam as dificuldades de alcançar, em breve, essa universalização.

3 Já foram produzidos, no âmbito desta pesquisa, outros artigos que abordam os debates dos RDHs sobre essas outras áreas do desenvolvimento humano. Ver: Rezende (2007a, b, 2008a, b, 2009, 2010).

4 Observe-se que esse debate sobre se há, ou não, efeitos positivos da habilitação por intermédio da educação não diz respeito somente aos países extremamente desiguais. Gøsta Esping-Andersen (2007, p. 194) ao discutir que tipo de Estado de bem-estar social pode-se esperar nos países europeus, para o século XXI, afirma que as políticas habilitadoras gerarão novas desigualdades. Segundo ele, democratizar as habilidades é um dos maiores desafios. Para ele, é simplório supor que através da educação todos podem ser inseridos no mercado de trabalho. "A educação, o treinamento e o aprendizado vitalício podem não ser o bastante. Uma economia intensiva em habilidades produzirá novas desigualdades [...]”. ${ }^{5}$ Há, na América Latina, hoje, um farto debate sobre a educação como política social indispensável para solucionar os problemas da empregabilidade e da pobreza. José Luís Corragio (1998, p. 5 apud ZICCARDI, 2002, p. 102) afirma: "A educação por si só não contribui para melhorar a condição competitiva dos trabalhadores em seu conjunto frente ao capital [...]".

${ }^{6}$ O livro de François Dubet intitulado As desigualdades multiplicadas (2003, p. 33) faz uma reflexão que pode ser tomada em defesa do enfoque habilitador. Pensando na França, ele afirma que a massificação escolar levou a uma democratização segregadora, "[...] pois os filhos das classes populares encontram-se especialmente nas carreiras e nas formações menos valorizadas e menos bem pagas [...]", mas "[...] a igualdade cresceu porque os estudos de longa duração não são mais um bem raro [...]”.

${ }^{7}$ Há um documento da CEPAL (Comissão Econômica para a América Latina das Nações Unidas) intitulado El Desarrollo Social de América Latina en la Postguerra (COMISSÃO ECONÔMICA PARA A AMÉRICA LATINA E O CARIBE, 1963) que propõe a expansão dos serviços educativos e sociais no continente como fator essencial de melhoria do bem-estar. 
${ }^{8}$ Gunnar Myrdal era técnico graduado das Nações Unidas. Produziu muitas discussões sobre desenvolvimento e bem-estar social.

${ }^{9}$ A coletânea de textos sobre educação e desenvolvimento, a qual foi organizada por Luiz Pereira e Marialice Forrachi (1987), traz uma ampla discussão sobre isto.

10 Técnicos da CEPAL, do PNUD, da UNESCO podem ser citados como exemplo.

11 Governo de Cristovam Buarque entre 1995 e 1998.

12 Ver: Waiselfisz (1998).

13 "Alguns têm considerado o desenvolvimento humano como 'desenvolvimento dos recursos humanos’. Mas investir nas pessoas, ou seja, na formação do capital humano, é somente um de seus aspectos. Ficam por fora todos os aspectos da participação, ou seja, o desenvolvimento pelas pessoas e para as pessoas. Outros têm apresentado o desenvolvimento humano como um assunto setorial, ou seja, como um investimento em educação, saúde e outros serviços sociais. Mas o desenvolvimento humano também é uma preocupação de política multissetorial e macroeconômica. Seu objetivo é garantir que o crescimento econômico se traduza em um bem-estar melhorado das pessoas [...]” (RELATÓRIO DE DESENVOLVIMENTO HUMANO, 1991, p. 38).

${ }^{14}$ O RDH de 1991 fazia uma proposta de ampliação da noção de desenvolvimento humano contida no RDH de 1990. "O desenvolvimento deve ser das pessoas, pelas pessoas e para as pessoas [...]” (RELATÓRIO DE DESENVOLVIMENTO HUMANO, 1991, p. 41). Assim, a sociedade deve investir em educação, saúde, nutrição e bem-estar de seus membros. Observe-se que o relatório insiste que a prioridade de investimento é da sociedade, o que já sinaliza uma proximidade com as posturas que defendem uma passagem da noção de Estado de bem-estar social para sociedade de bem-estar. Tony Judt (2011, p. 22) critica essa visão e alerta para a necessidade de "reconceber o papel do governo", e do Estado neste processo.

15 Estas expressões "países menos desenvolvidos" e "países em desenvolvimento" são utilizadas pelos RDHs para diferenciar países como Chile, Argentina, Brasil, Peru, Costa Rica, Índia, etc. que fariam parte deste último grupo, de outros, tais como Níger, Somália, Sudão, Lesoto, Namíbia, Bangladesh, etc., que fariam parte daquele primeiro grupo. Caberia uma investigação sobre as razões de os relatórios utilizarem essas expressões. Norbert Elias (1994, p. 146) afirma que o sintagma "país em desenvolvimento" é vago e dissimula questões essenciais acerca do desenvolvimento social.

16 Certamente o RDH está se referindo à pobreza absoluta e não à pobreza de modo geral. 17 Plano de Erradicação da Miséria, lançado em 2011, pelo governo Dilma Rousseff (2011-2014).

18 Lena Lavinas (2011, p. 3) mostra-se, neste artigo, influenciada por Amartya Sen ao fazer a seguinte afirmação: "Como nos ensinou Amartya Sen, é igualmente necessário ser capaz de transformar renda em bem-estar, dotações básicas [educação, por exemplo] em meios de vida [...]". 
19 “As famílias no Punjab rural da Índia gastam duas vezes mais com atenção médica dos recém-nascidos do sexo masculino que com recém-nascidas [...]” (RELATÓRIO DE DESENVOLVIMENTO HUMANO, 1990, p. 77).

20 A ideia de governança defendida pelos relatórios assenta-se na construção de “[...] redes intergovernamentais auto-organizadas [...]" (RHODES, 1997, p. 3). O Estado é um dos agentes entre muitos outros (organizações não governamentais - ONGs, agências internacionais, organizações populares, associações diversas, etc.). Sobre o conceito de governança, ver: (JESSOP, 1990). Sobre a governança de múltiplos níveis ver Smith (2010).

21 Todos esses aspectos foram detalhadamente trabalhados no RDH (RELATÓRIO DE DESENVOLVIMENTO HUMANO, 1992).

Recebido: 04/11/2011

Aprovado: 11/05/2012

Contato:

Universidade Estadual de Londrina

Departamento de Ciências Sociais

Rod. Celso Garcia Cid

$\operatorname{Pr} 445 \mathrm{Km} 380$, Campus Universitário

CEP 86051-980

Paraná, PR

Brasil 